\title{
BIOAKTIVITAS EKSTRAK KULIT BATANG TUMBUHAN LANGKA MERANTI LILIN (SHOREA TEYSMANIANA DIER)
}

\author{
Jufrizal Syahri, Kamal Rullah, Sri Hilma Siregar \\ Universitas Muhammadiyah Riau, Sekolah Tinggi Ilmu Farmasi Riau \\ Email: jsyachri@gmail.com
}

\begin{abstract}
ABSTRAK
Tumbuhan Shorea teysmaniana Dier adalah tumbuhan khas Provinsi Riau yang sudah langka dan dikenal dengan nama Meranti Lilin. Kulit batang tumbuhan ini diekstrak dengan metoda maserasi, sehingga didapatka ekstrak heksan 40,69 g, ekstrak etilasetat 133,22 g, dan ekstrak methanol 386,29 g. Masingmasing ekstrak dilakukan uji antibakteri dengan metoda difusi dan uji anti oksidan dengan metoda DPPH. Uji antibakteri dilakukan terhadap bakteri Escherichia coli, Staphylococcus aureus, Sallmonella typhii, Bacillus subtilis dengan konsentrasi 1\%. Ekstrak heksana tidak menunjukkan aktivitas, ekstrak etilasetat memberikan zona bening berturut-turut $(\mathrm{mm}) 13,2 ; 12,3 ; 9,6 ; 9 ; 9$. Ekstrak metanol menunjukkan aktifitas dg membentuk zona bening berturut-turut $(\mathrm{mm}) 10,6 ; 10,3 ; 8,1 ; 11,0$. Berdasarkan aktivitas inilah proses isolasi dilanjutkan dengan menggunakan kromatografi vacum cair sehingga dihasilkan 12 fraksi untuk setiap ekstraknya. Ekstrak aktif dilanjutkan untuk diisolasi sampai senyawa murni, untuk ekstrak etil asetat menghasilkan 2 senyawa murni dengan kode HT1 dan HT2.
\end{abstract}

Kata kunci: Bakteri, Shorea teysmaniana Dier dan zona bening

\section{PENDAHULUAN}

Tumbuhan S.teysmaniana Dier sering dikenal dengan nama daerah Riau yaitu Meranti Lilin, adalah salah satu spesies yang termasuk genus utama dari tumbuhan famili Dipterocarpaceae yang merupakan tanaman langka di Indonesia. Kelangkaan tumbuhan ini dikarenakan memiliki nilai ekonomi yang sangat tinggi, yaitu sebagai bahan baku bangunan, industri kayu lapis, industri PULP dan Peaper. Sementara itu ditinjau dari sisi bioaktivitasnya belum ada peneliti yang melaporkannya, sehingga sangat perlu dilakukan penelitian terhadap bioaktivitas kandungan senyawa kimia dari kulit batang meranti lilin ini.

Penelusuran literatur terhadap tumbuhan genus Shorea diketahui bahwa sudah mulai banyak penelitian yang mengungkapkan kandungan senyawa metabolit sekunder dan bioaktivitasnya. Penelitian yang telah dilaporkan yaitu penelitian terhadap kulit batang Shorea seminis V.Sl dan berhasil mengisolasi senyawa Laevifonol (1), Diptoindonesin A (2), dan Ampelopsin A (3), namun aktivitasnya tidak dilaporkan (Aminah et al, 2003). Syahri et al, 2010 berhasil mengisolasi senyawa bergenin (4), yang memiliki bioaktivitas sebagai antibakteri. Semua senyawa yang ditemukan ini merupakan senyawa fenolik dan tergolong kedalam oligostilbenoid. Karena senyawa golongan fenolik memiliki aktivitas yang sangat banyak, dan berpotensi untuk dijadikan sebagai bahan dasar obat, maka perlu dilakukan penelitian lebih lanjut terhadap tumbuhan S.teysmaniana Dier untuk menemukan senyawa fenolik lain atau baru yang memiliki potensi sebagai obat.

Penelitian eksplorasi potensi kimia yang intensif pada tanaman ini akan memberikan kontribusi besar terhadap ilmu kimia khususnya pada genus Shorea. Hasil penelitian ini diharapkan menjadi sumber informasi baru mengenai kandungan metabolit sekunder pada tumbuhan S.teysmaniana Dier yang bermanfaat pada bidang pertanian, kehutanan, dan untuk pengembangan bidang kesehatan seperti antioksidan, antikanker, antimikroba, insektisida, dan fungisida. Dengan demikian dapat meningkatkan nilai tambah pemanfaatan tumbuhan S.teysmaniana dan merupakan aset daerah Riau yang bernilai ekonomi tinggi. 


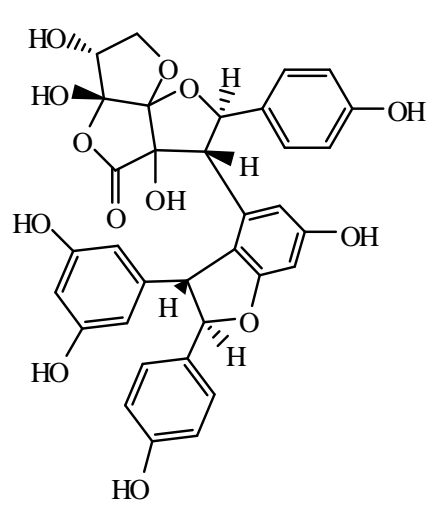

1. Leavifonol

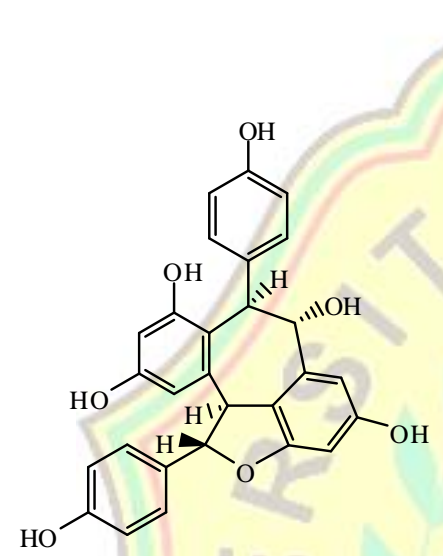

3. Ampelopsin A

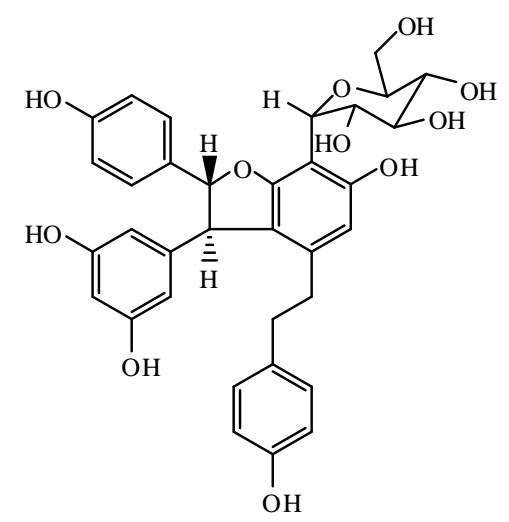

2. Diptoindonesin A

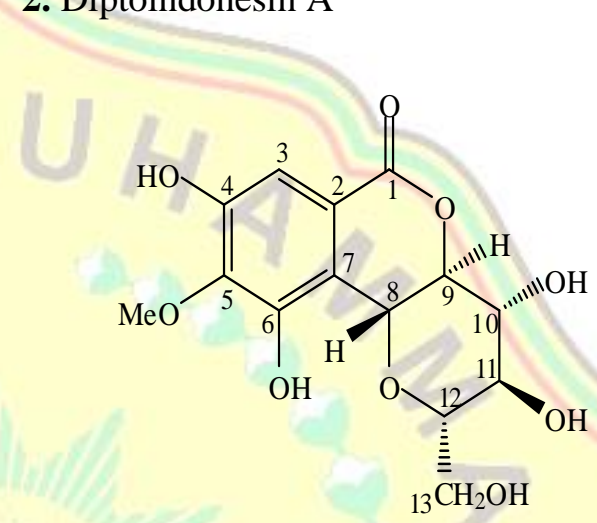

4. Bergenin
Manfaat penelitian ini memiliki dua arah yaitu untuk aplikasi dan pengembangan ilmu. Peningkatan nilai tambah bahan obat tradisional, pembenaran penggunaan di masyarakat sebagai obat alternatif merupakan salah satu kegunaan aplikasi. Dalam pengembangan ilmu, temuan penelitian berupa senyawa bioaktif dapat dikembangkan menjadi senyawa medisinal unggulan yang bernilai ekonomi tinggi. Penelitian ini sangat penting mengingat di negara maju alur pikir teknologi kesehatan saat ini tidak lagi menggunakan senyawa kimia sintetik, namun pencarian senyawa kimia alami tunggal atau campuran menjadi prioritas. Sehingga penelitian ini juga merupakan salah satu model pencarian devisa dari keanekaragaman hayati yang selama ini belum banyak dilakukan.

\section{METODOLOGI PENELITIAN}

Alat yang digunakan dalam penelitian ini adalah sebagai berikut: rotary evaporator Heidolph VV 2000, kromatografi kolom vakum cair berdiameter $5 \mathrm{~cm}$ dan tinggi $30 \mathrm{~cm}$, Chamber, peralatan distilasi, Melting Point Apparatus, lampu UV model UVL-56, spektrofotometer IR merk Shimadzu type IR Prestige-21, spektrofotometer UV-Visible merk Hitachi U-2001, spektrofotometer NMR merk JEOL type ECA 500 dengan medan magnet 500 $\mathrm{MHz}$, inkubator, cawan petri, pipet mikro, dan peralatan lainnya yang sesuai prosedur kerja

Sampel yang digunakan adalah kulit batang dari tumbuhan Shorea teysmaniana Dier. Bahan yang digunakan adalah pelarut teknis untuk isolasi dan pelarut pure analitis untuk analisis spektroskopi, silika gel $60 \mathrm{GF}_{254}$ (Merck, No. katalog 1.07730.1000), reagen penampak noda anisaldehid $(0,5 \mathrm{~mL}$ anisaldehid $+50 \mathrm{~mL}$ asam asetat glasial $+9 \mathrm{~mL} \mathrm{H}_{2} \mathrm{SO}_{4}$ pekat), plat KLT $\mathrm{GF}_{254}$ (Merck, No. katalog 1.05554.0001, 60 $\mathrm{F}_{254}$ ), dan aquadest. Bakteri yang digunakan yaitu: Escherichia coli, Staphylococcus aureus, Sallmonella typhii, Bacillus subtilis. 
Sebanyak 5 kg kulit batang Shorea teysmaniana dibersihkan dengan sikat kawat. Selanjutnya sampel yang telah dibersihkan di keringanginkan terlebih dahulu hingga kering lalu di dihaluskan sampai pada kehalusan tertentu hingga diperoleh sebuk kering kulit batang Shorea teysmaniana Serbuk kering kulit kemudian direndam dengan pelarut $n$-heksana didalam bejana ekstraksi untuk menarik senyawasenyawa non-polarnya, lalu disaring. Proses ekstraksi dilakukan berulang-ulang hingga ekstrak yang keluar tidak berwarna atau tidak menampakkan noda bila ditotolkan pada plat KLT. Ekstrak yang didapat diuapkan dari pelarutnya menggunakan alat destilasi vakum dan rotary evaporator, sehingga didapat ekstrak kental $n$-heksana sebanyak 40,69 g yang berwarna coklat muda. Prosedur yang sama juga dilakukan untuk menarik senyawa-senyawa semi polar dan polar, yang masing-masingnya berturut-turut menggunakan etilasetat dan methanol, sehingga didapatkan ekstrak kental etilasetat sebanyak 133,22 g berwarna coklat tua, dan ekstrak kental methanol sebanyak 386,29 g berwarna coklat kehitaman.

Uji aktivitas antibakteri ekstrak kulit batang meranti lilin (Shorea teysmaniana) terhadap bakteri Staphylococcus aureus, Escherichia coli, Sallmonella typhi dan bacillus subtilis dengan menggunakan metode difusi agar. Prosedur pengujian aktivitas antibakteri adalah bakteri uji di inokulasikan kedalam media Nutrient Broth (NB) sebanyak 3 jarum ose, diinkubasi selama 24 jam pada suhu $37^{\circ} \mathrm{C}$. Suspensi bakteri hasil inkubasi dikocok dengan alat pemutar kemudian diukur transmitannya pada panjang gelombang $580 \mathrm{~nm}$. Transmitan (T) diatur sebesar $25 \%$ dengan cara penambahan bakteri atau medium cair, suspensi bakteri $\mathrm{T} 25 \%$ dimasukkan kedalam cawan petri $0,3 \mathrm{~mL}$, kemudian ditambahkan medium Nutrient Agar (NA) $10 \mathrm{~mL}$ yang belum membeku. Dengan suhu sekitar $40^{\circ} \mathrm{C}$. Selanjutnya digoyang-goyang sampai membeku. Kedalam medium yang berisi bakteri dimasukkan kertas cakram $6 \mathrm{~mm}$ dan ditetesi dengan $10 \mu \mathrm{L}$ larutan ekstrak dengan konsentrasi $1 \%$ dalam pelarut $n$-heksana, methanol, etilasetat, dan diinkubasi selama 24 jam pada suhu $37{ }^{\circ} \mathrm{C}$ diukur diameter hambatan yang terbentuk. (Niwa, 1997).

Uji antioksidan dilakukan dengan menimbang sebanyak $0,0050 \mathrm{~g}$ ekstrak kulit batang meranti lilin (Shorea teysmaniana) kemudian dilarutkan dalam labu ukur $5 \mathrm{~mL}$ dengan metanol didapat konsentrasi larutan stok ekstrak 1000 ppm. larutan stok dipipet dilarutkan dalam $5 \mathrm{~mL}$ metanol untuk mendapatkan larutan $(500,250,125,62.5,31.3$ ppm). Pada masingmasing konsentrasi dipipet $50 \mu \mathrm{L}$ masukkan dalam plate dengan pengulangan tiga kali, ditambahkan $120 \mu \mathrm{L}$ metanol dan ditambahkan DPPH $80 \mu \mathrm{L}$ dengan konsentrasi $400 \mathrm{ppm}$ diinkubasi selama 30 menit ditempat gelap pada suhu ruang. Kemudian ukur serapan dengan microplate reader 96 dengan panjang gelombang $517 \mathrm{~nm}$ (Su Zhi-heng et al 2010). Aktivitas antioksidan sampel ditentukan oleh besarnya hambatan serapan radikal DPPH melalui perhitungan persentase inhibisi serapan DPPH dengan menggunakan rumus (Andayani, 2008).

\section{$\%$ Inhibisi $=$ Abs. Kontrol - Abs.sampel $\times 100 \%$ \\ Abs. Kontrol}

Sebanyak $25 \mathrm{~g}$ ekstrak etilasetat dipisahkan dengan menggunakan kromatografi vakum cair (KVC) dengan menggunakan silika gel $60 \mathrm{PF}_{254}$ ukuran 40-63 $\mu \mathrm{m}$ (230-400 mesh) sebagai fase diam. Diameter kolom yang digunakan $5 \mathrm{~cm}$ dan tinggi silika $10 \mathrm{~cm}$. Pengelusian dilakukan menggunakan fase gerak $n$-heksana, etilasetat dan metanol dengan metode SGP (Step Gradient
Polarity) yaitu metode elusi di mana pelarut ditingkatkan kepolarannya secara bertahap dalam berbagai perbandingan. Volume fase gerak yang digunakan masing-masing adalah $150 \mathrm{ml}$

Hasil KVC ini mendapatkan 15 fraksi, namun setelah dilakukan Kromatografi Lapis Tipis (KLT) beberapa fraksi memiliki Rf yang hampir sama yaitu fraksi (5 dan 6) dan fraksi (7 
dan 8), sehingga fraksi yang memiliki Rf sama ini digabungkan dan akhirnya diperoleh 13 fraksi saja. Pada fraksi 3 terdapat bayangan Kristal (senyawa), dan dari hasil KLT menunjukkan 2 noda sehingga dilakukan pemisahan lebih lanjut dengan menggunakan kolom kromatografi gravitasi dan rekristalisasi diperoleh senyawa murni berwarna putih dan diberi kode HT1. Penentuan kemurnian dilakukan dengan menggunakan HPLC, dan memberikan satu peak (puncak) yang menunjukkan senyawa HT1 sudah murni.

Gabungan fraksi 5 dan 6 disebut FG1, FG1 memiliki berat 2,4 g lalu dilakukan pemisahan lanjutan dengan mengguankan kromatografi kolom grafitasi dan diperoleh sebanyak 123 vial. Pada fial 12-24 terdapat senyawa berbentuk Kristal, namun setelah dilakukan pengecekan menggunakan KLT masih terdapat 3 noda, sehingga masih perlu dilakukan pemisahan lebih lanjut dengan menggunakan kolom kromatografi preparative, dan diperoleh senyawa murni dengan kode HT2. Kedua senyawa murni ini dilakukan pengujian profil fitokimia untuk menentukan golongan senyawanya.

\section{HASIL DAN PEMBAHASAN}

Hasil uji aktivitas antibakteri menunjukkan bahwa ekstrak methanol dan etilasetat aktif terhadap bakteri uji sedangkan ekstrak $n$-heksana tidak aktif. Ekstrak methanol mempunyai diameter hambatan terhadap Escherichia coli 13,2 mm, Ekstrak etilasetat mempunyai diameter hambatan terhadap Escherichia coli 10,6 mm, Ekstrak methanol mempunyai diameter hambatan terhadap Staphylococcus aureus $12,3 \mathrm{~mm}$, Ekstrak etilasetat mempunyai diameter hambatan terhadap Staphylococcus aureus 10,3 mm, Ekstrak methanol mempunyai diameter hambatan terhadap Sallmonella typhi 9,6 mm, Ekstrak etilasetat mempunyai diameter hambatan terhadap Sallmonella typhi $8,1 \mathrm{~mm}$, Ekstrak methanol mempunyai diameter hambatan terhadap bacillus subtilis 9,9 mm (Gambar 1), Ekstrak etilasetat mempunyai diameter hambatan terhadap bacillus subtilis $11,0 \mathrm{~mm}$.

Tabel 1. Hasil uji aktivitas antibakteri ekstrak $n$-heksana, etilasetat, methanol dari kulit batang S.teysmaniana

\begin{tabular}{|c|c|c|c|c|c|c|}
\hline \multirow{2}{*}{ No } & \multirow{2}{*}{$\begin{array}{c}\text { Jenis } \\
\text { Ekstrak }\end{array}$} & $\begin{array}{c}\text { Konsentrasi } \\
\mathbf{m g} / \mathbf{m l}\end{array}$ & $\begin{array}{c}\text { Escherichia } \\
\text { coli }\end{array}$ & $\begin{array}{c}\text { Staphylococcus } \\
\text { aureus }\end{array}$ & $\begin{array}{c}\text { Sallmonella } \\
\text { typhii }\end{array}$ & $\begin{array}{c}\text { Bacillus } \\
\text { subtilis }\end{array}$ \\
\hline 1. & $n$-Heksana & 10 & 0 & 0 & 0 & 0 \\
\hline 2. & Methanol & 10 & 13,2 & 12,3 & 9,6 & 9,9 \\
\hline 3. & Etilasetat & 10 & 10,6 & 10,3 & 8,1 & 11,0 \\
\hline
\end{tabular}
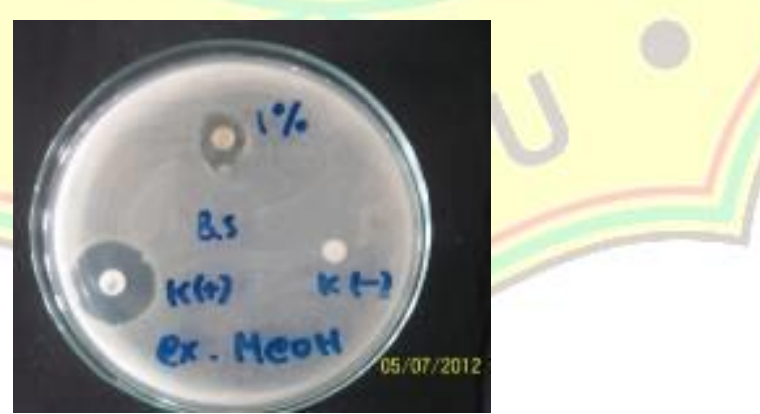

\section{Gambar 1. Hambatan antibakteri ekstrak metanol terhadap koloni bacillus subtilis}

Hasil pengujian aktivitas antioksidan pada masing-masing ekstrak, didapati ekstrak nheksana, etilasetat dan metanol memiliki nilai $\mathrm{IC}_{50}$ terhadap radikal bebas DPPH berturut-turut sebesar $>1000 \mu \mathrm{g} / \mathrm{ml}, 260 \mu \mathrm{g} / \mathrm{ml}$, dan $67 \mu \mathrm{g} / \mathrm{ml}$. Ekstrak metanol dan ekstrak etilasetat memiliki aktivitas antioksidan yang tinggi karena pada kedua-dua fraksi ini banyak terdapat senyawa semi polar dan polar seperti senyawa fenolik dan senyawa polifenol yang umumnya bersifat antioksidan. 
Tabel 2. Hasil uji aktivitas sitotoksik ekstrak kulit batang Shorea teysmaniana

\begin{tabular}{|l|l|l|}
\hline No & \multicolumn{1}{|c|}{ Ekstrak } & Nilai IC $_{\mathbf{5 0}}$ \\
\hline 1 & $n$-heksana & $>1000 \mu \mathrm{g} / \mathrm{ml}$ \\
\hline 2 & Etilasetat & $260 \mu \mathrm{g} / \mathrm{ml}$ \\
\hline 3 & Metanol & $67 \mu \mathrm{g} / \mathrm{ml}$ \\
\hline 4 & Asam askorbat (Vit C) & $5,9 \mu \mathrm{g} / \mathrm{ml}$ \\
\hline
\end{tabular}

Hasil isolasi senyawa dari ekstrak etilasetat diperoleh 2 senyawa murni dengan kode HT1dan HT2 yang dibuktikan dengan memberikan satu puncak setelah dianalisis menggunakan HPLC (Gambar 2). Hasil pengujian fitokimia kedua senyawa ini menunjukkan bahwa senyawa HT1 dan HT2 merupakan golongan senyawa fenolik.

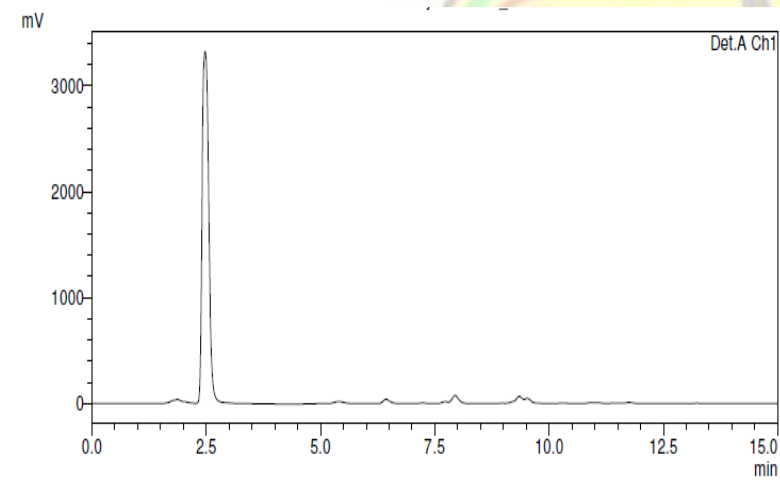

Gambar 2. Hasil analisis senyawa HT1 dengan menggunakan HPLC

\section{KESIMPULAN}

Tumbuhan Shorea teysmaniana Dier (Meranti Lilin) memiliki potensi sebagai salah satu obat alternative, ini terbukti bahwa tumbuhan khas Riau ini mengandung senyawa aktif antimikroba, dan antioksidan, terlihat dari aktivitas ekstrak terhadap uji antimikroba dan antioksidan.

\section{DAFTAR PUSTAKA}

Aminah, N.S., Achmad, S.A., Hakim, E.H., Syah, Y.M., Juliawaty, L.D., dan Ghisalberti, E.L. (2003). Laevifonol, Diptoindonesin A, dan Ampelopsin A, Tiga Dimer Stilbenoid dari Kulit Batang Shorea seminis V. Sl. (Dipterocarpaceae). Jurnal Matematika dan Sains. 8 (1). 31-34

Syahri, J. (2010). Bergenin dari kulit batang Shorea seminis V.Sl dan uji aktivitasnya sebagai antibakteri

Niwa, Y., 1997, Radikal Bebas Mengundang Kematian, NTV. Japan, Personal Care Co. Ltd, 9-10; 19 dan 30.

Zheng, Z., Zhao, S., Deng, J-Z, Zhu, F., (1995). Isolation and identification of resveratrol 4C-glucoside., Zongguo Yaoke Daxue Xuebao (Chinese), 26, 5-7. 